\title{
Pattern of anaemia in Fayoum governorate
}

Mohamed A Mashahet ${ }^{1}$, Rehab Mahmoud A ${ }^{2}$, El-Shafee $\mathrm{S}^{3}$, Eman M Ezzat ${ }^{4}$,

1. Professor and head of Internal Medicine department, Faculty of Medicine, Fayoum University.

2. M.B.B.CH, Fayoum University, Egypt.

3. .Professor .of clinical pathology, Faculty of medicine, Fayoum University.

4. .Lecturer of Internal Medicine, Faculty of Medicine, Fayoum University.

Abstract: anemia is highly prevalent in Fayoum Governorate, females most commonly affected and IDA is the most common type.

Introduction: Anemia is a condition in which the hemoglobin level is below normal and insufficient to meet physiologic needs. The World Health Organization (WHO), 2011 estimates suggest anemia affects around 800 million children and women, on average, all population groups were above the threshold for mild anemia. So, we aimed to study the pattern of anemia in Fayoum Governorate.

Patients and Methods: This real practice study included 1500 patients with different types of anaemia. All patients were subjected to a full medical history, full clinical examination, blood sample for complete blood count (CBC) examination, serum iron, and serum ferritin concentration.

Results: This study included 1500 patients having a female predominance with a male to female ratio as ( $45.47 \%$ and $54.53 \%)$ respectively. The mean age of patients was $48.9 \pm 18.1$ years. Anaemia was more common in the age group between 50-65 years. Most common associated comorbidities were diabetes mellitus (DM) and hypertension (HTN) by $65.1 \%$ and $61 \%$ respectively. The most common causes of anemia were chronic kidney disease (CKD), chronic liver disease (CLD), Malignancy by $27.1 \%, 21.93 \%, 15.8 \%$ respectively.

Conclusion: There is more prevalence of anaemia in females in Fayoum Governorate. This prevalence is increasing with age. Here iron deficiency anemia (IDA) is the most common type of anemia in pregnant females. There is a common association between anaemia with diabetes mellitus in absence of CKD.

Key words: Anaemia, Fayoum

Governorate.

\section{Introduction:}

Anemia is a common health concern, especially for premenopausal women and the aging population. A Previous research had shown that anemia can increase the risk of morbidity as well as mortality [1]. 
The global prevalence of anaemia in 2013 had shown to be a public health problem that affect low-, middle- and high-income countries and had a significant adverse health consequences, as well as adverse impacts on social and economic development [2]. Iron deficiency (ID) is in the top 20 risk factors for the global distribution of burden of disease, and the most common nutritional disorder and the leading cause of anemia in the world [3].

Although the prevalence of anemia was estimated at $9 \%$ in countries with high development, in countries with low development the prevalence was $43 \%$ (4).

Anaemia is more common in children and women; it increases the risk of maternal and neonatal adverse outcomes. Anaemia affects half a billion women of reproductive age worldwide. Anemia has many aetiologies, manifestations, types and complications [4].

\section{Aim of the work:}

The incidence of anemia in Egypt (as developing countries) is much higher than developed countries so the present study was aimed to investigate the pattern of anemia in El Fayoum Governorate in Egypt.

\section{Patient and methods:}

This study included 1500 anaemic patients their ages above 18 years, it was conducted from December 2017 to December

2018.They were recruited from internal

medicine outpatient clinics at Fayoum university hospital, Insurance hospital and Fayoum General hospital. All patients were subjected to a full medical history, full clinical examination, blood sample for (if not available) complete blood count (CBC) examination, serum iron and serum ferritin concentration. Other Investigations were asked if indicated (Reticulocytic count, bone marrow aspiration and biopsy, occult blood in stool).

\section{Statistical analysis of data:}

The collected data were organized, tabulated and statistically analyzed using SPSS software statistical computer package version 22 (SPSS Inc, USA). For quantitative data, the mean and standard deviation (SD) were calculated. One way ANOVA was used in comparing between the study groups. Qualitative data were presented as number and percentages, chi square $\left(\chi^{2}\right)$ was used as a test of significance. For interpretation of results of tests of significance, significance was adopted at $\mathbf{P} \leq \mathbf{0 . 0 5}$. 


\section{$\underline{\text { Results: }}$}

This study was conducted on 1500 anaemic patients, males were 682 (45.47\%) while females were 818 (54.53\%), With mean age of the study group was $48.9 \pm 18.1 \mathrm{SD}$ as shown in table 1, anaemia was highly prevalent in the age group ranged between 50-65 years.

Table (1): Socio-demographic characteristics of the studied patients.

\begin{tabular}{|l|c|c|c|c|c||}
\hline \multirow{2}{*}{ Groups } & \multirow{2}{*}{ Age } & \multicolumn{4}{|c|}{ Sex } \\
\cline { 2 - 6 } & & \multicolumn{2}{|c|}{$\begin{array}{c}\text { Male } \\
(\mathrm{T}: 682)\end{array}$} & \multicolumn{2}{c|}{$\begin{array}{c}\text { Female } \\
(\mathrm{T}: 818)\end{array}$} \\
\cline { 2 - 6 } & Mean \pm SD & $\mathbf{N}$ & $\%$ & $\mathbf{N}$ & $\%$ \\
\hline Pregnancy & $26 \pm 5$ & - & - & & \\
\hline $\begin{array}{l}\text { Bleeding (no } \\
\text { trauma) }\end{array}$ & $43 \pm 18$ & 81 & $11.9 \%$ & 158 & $19.3 \%$ \\
\hline Parasites & $47 \pm 19$ & 50 & $7.3 \%$ & 59 & $7.2 \%$ \\
\hline Hemolytic & $27 \pm 8$ & 31 & $4.5 \%$ & 92 & $11.2 \%$ \\
\hline Malignant & $55 \pm 13$ & 87 & $12.8 \%$ & 150 & $18.3 \%$ \\
\hline CKD and CLD & $58 \pm 13$ & 52 & $7.6 \%$ & 22 & $2.7 \%$ \\
\hline CKD & $55 \pm 15$ & 227 & $33.3 \%$ & 105 & $12.8 \%$ \\
\hline CLD & $63 \pm 9$ & 130 & $19.1 \%$ & 83 & $10.1 \%$ \\
\hline $\begin{array}{l}\text { Other chronic } \\
\text { diseases }\end{array}$ & $47 \pm 20$ & 24 & $3.5 \%$ & 32 & $3.9 \%$ \\
\hline
\end{tabular}

CKD: chronic kidney disease.

CLD: chronic liver disease.

Regarding comorbidities in the studied patients it was found that the most prevalent co morbidity was diabetes mellitus $(65.1 \%)$ followed by hypertension $(61 \%)$ as shown in table 2 .

Table (2): Co- morbidities among the studied patients.

\begin{tabular}{|l|l|l|}
\hline Variable & $\mathbf{N}$ & $\%$ \\
\hline
\end{tabular}




\begin{tabular}{||l|c|c|}
\hline DM & $\mathbf{9 7 7}$ & $\mathbf{6 5 . 1 \%}$ \\
On Insulin & 487 & 49.8 \\
On Oral hypoglycemic & 490 & 50.1 \\
& & \\
& & $61 \%$ \\
\hline \hline HTN & 915 & $96.3 \%$ \\
Primary & 881 & $3.7 \%$ \\
Secondary & 34 & \\
\hline
\end{tabular}

DM: Diabetes mellitus.

HTN: Hypertension.

Regarding CKD patients they were 406 (27.1\%) patients among them 279 (68.72\%) were males and $127(31.28 \%)$ were females.

There were 297 patients suffering from both HTN and CKD which represented $(73.15 \%)$ of CKD patients and $(32.45 \%)$ of hypertensives.

In the present study there were 320 patients $(21.33 \%)$ of those having CKD suffering from DM, HTN

Regarding CLD patients they were 213 (14.2\%) patients (without bleeding or renal impairement) among them $(40.73 \%)$ were HCV infection and $(24.1 \%)$ were HBV infection there were $12.76 \%$ with acute variceal bleeding and $22.49 \%$ were suffering from combined CLD and CKD as shown in table 3.

Table (3): Causes of anaemia among the studied group.

\begin{tabular}{|c|c|c|c|}
\hline \multicolumn{2}{|c|}{ Variable } & $\overline{\mathbf{N}}$ & $\overline{\%}$ \\
\hline \multicolumn{2}{|l|}{$\overline{\text { CKD }}$} & 406 & $27.1 \%$ \\
\hline \multirow{3}{*}{$\begin{array}{c}\mathrm{HCV}-\mathrm{ve} \\
\mathrm{N}=332 \\
(81.77 \%)\end{array}$} & Hemodialysis & 234 & 70.5 \\
\hline & On Iron and EPO & 290 & 87.3 \\
\hline & $\begin{array}{l}\text { On regular } \\
\text { transfusion }\end{array}$ & 290 & 87.3 \\
\hline \multirow{2}{*}{$\begin{array}{c}\mathrm{HCV}+\mathrm{ve} \\
\mathrm{N}=74 \\
(18.23 \%)\end{array}$} & Hemodialysis & 60 & 81.1 \\
\hline & On Iron and EPO & 55 & 74.3 \\
\hline
\end{tabular}




\begin{tabular}{||l|c|c|}
\hline \multicolumn{1}{|c|}{$\begin{array}{c}\text { On regular } \\
\text { transfusion }\end{array}$} & 39 & 52.7 \\
\hline Malignancy & 237 & $15.8 \%$ \\
On chemotherapy & 206 & $86.92 \%$ \\
On radiotherapy & 10 & $4.22 \%$ \\
Not treated yet & 21 & $8.86 \%$ \\
\hline CLD & 329 & $21.93 \%$ \\
HCV+ve & 134 & $40.73 \%$ \\
HBV+ve & 79 & $24.01 \%$ \\
Acute bleeding haematemesis & 42 & $12.76 \%$ \\
CLD + CKD & 74 & $22.49 \%$ \\
\hline Hemolytic anemia & 123 & $8.2 \%$ \\
\hline \hline Others: autoimmune, cardiac & 165 & $11 \%$ \\
\hline
\end{tabular}

CKD: chronic kidney disease.CLD: chronic liver disease. Epo: erythropoietin hormone. HCV: hepatitis $\mathrm{C}$ virus. HBV: hepatitis B virus.

In the studied group, the highest mean haemoglobin level were found in the group affected with intestinal parasites by $(10.08 \pm 0.79 \mathrm{SD})$ and the least level were in group of hemolytic anemia by $(8.01 \pm 1.61 \mathrm{SD})$ as shown in figure 1 .

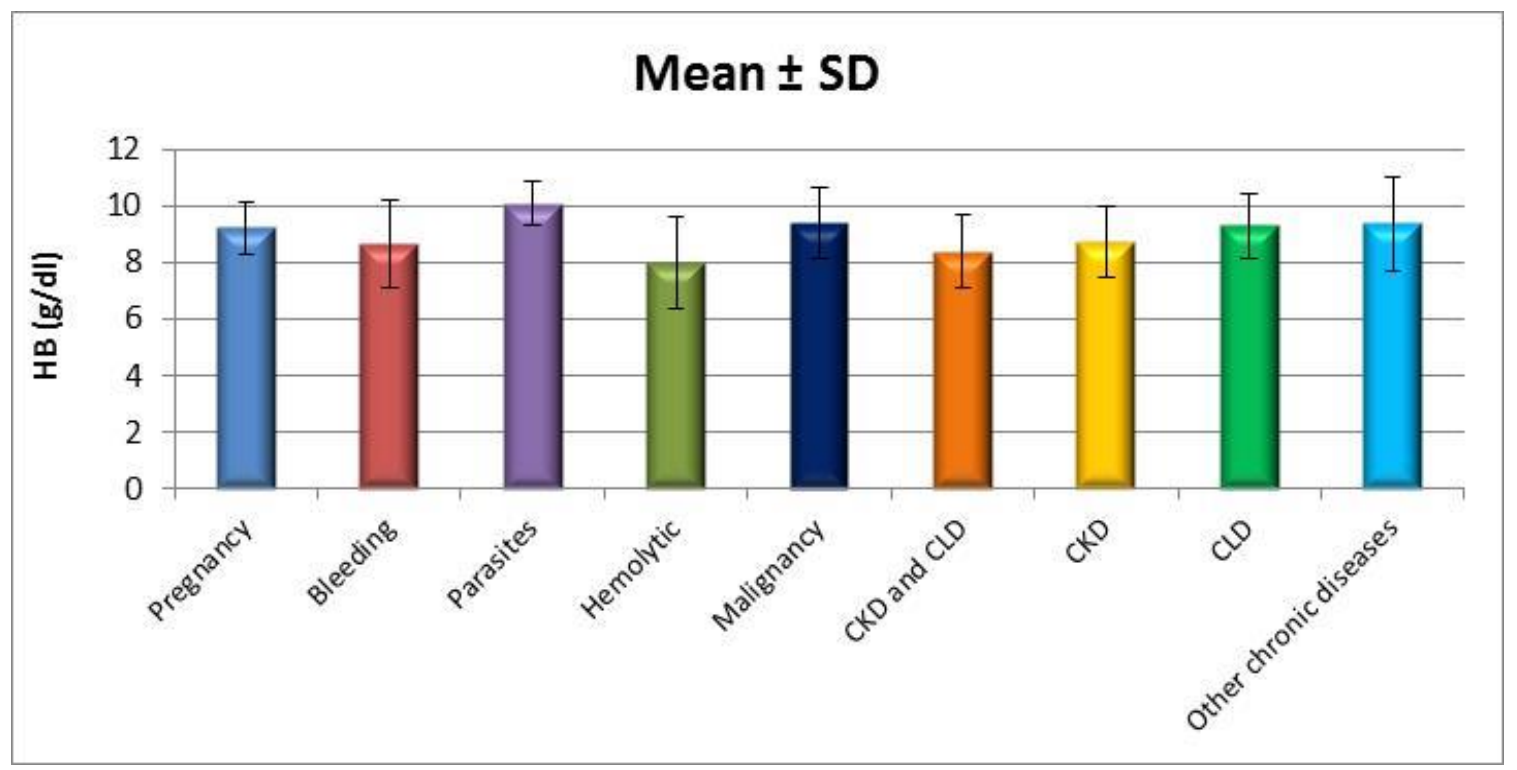

Figure (1): Mean haemoglobin levels with SD among the studied groups. 


\section{Discussion:}

This study included 1500 anaemic patients aiming to investigate the pattern of anemia in El Fayoum Governorate in Egypt.

Our results showed that anaemia was highly prevalent in the age group ranged between 50-65 years by 498 (33.2\%). Also, we found that the most common comorbidity was DM by 977 (65.1\%), followed by HTN by 915 (61\%), included patients with CKD 406 (27.1\%), with malignant diseases 237 (15.8\%), CLD patients were 329 (21.93\%) and 564 (37.6\%) were active cigarette smokers.

These results are in agreement with Gandhi et al., 2017 who revealed that a higher prevalence of anemia was associated with advancing age and comorbidities. But the most common co morbidity was the essential HTN represented 59.3\%, Diabetes mellitus $19.4 \%$, chronic kidney disease $11.1 \%$, malignancy $18.5 \%$, chronic liver disease $6.5 \%$ and $11.6 \%$ were active cigarette smokers ${ }^{[5]}$.

In this study showed females predominance as regarding the sex including (682 were males $(45.47 \%), 818$ (54.53\%) were females) that was consistent with
Callera et al., 2015 who found that $35.1 \%$ were males and $64.9 \%$ were females ${ }^{[6]}$.

Our results showed that the mean age of $48.9 \pm 18.1 \mathrm{SD}$ which is not agreed with El-Arbagy et al., 2015 who founded that the mean age of the patients was $44.5+/-12.3$ years. The lower mean age in our study may be due to the large number of patients on dialysis ${ }^{[7]}$.

The current study documented that microcytic anaemia was more common than normocytic anaemia in the studied group as $1179(78.6 \%)$ patients had microcytic anemia however 321 (21.4\%) only had normocytic anemia with different values of mean haemoglobin levels according to the cause of anemia with the highest mean haemoglobin level were found in the group affected with intestinal parasites by (10.08 \pm $0.79 \mathrm{SD})$ and the least level were in group of hemolytic anemia by $(8.01 \pm 1.61 \mathrm{SD})$.

This was in agreement with Sharourou et al., 2018 who found that the most important cause of anemia was iron deficiency anaemia ${ }^{[8]}$.

\section{Also, Al Hassan., 2015 found that} iron deficiency anaemia was the most common type of anaemia represented $81 \%$ 
with mean hemoglobin concentration for the study sample was $9.8 \pm 7 \mathrm{~g} / \mathrm{dl}^{[9]}$.

Also, Salama et al., 2016 were agreed with this study as the mean haemoglobin of the anaemic patients was $10.5 \mathrm{~g} / \mathrm{dl}^{[10]}$

This was not in line with Mengesha and Dadi., 2019 who revealed that the most common anemia was normocytic by $52 \%$ of anaemic subjects ${ }^{[11]}$. This may be due to the different numbers and characteristics of populations in both studies as their study include only 400 patients who are men and non-pregnant women.

Also, Zaninetti et al., 2018 stated that chronic inflammation and chronic renal failure were the most frequent causes of anemia ${ }^{[12]}$.This may be explained as Zaninetti study included only hospitalized patients.

El-Arbagy et al., 2015 disaggreed with our results regarding sex with men and women percentage were $65.7,34.3 \%$ respectively ${ }^{[7]}$.

In addition Portolés et al., 2013 found that the mean age was $65 \mathrm{y}$ with range of (24-78), but this study included anemic and non-anemic CKD patients ${ }^{[13]}$.

\section{Limitations:}

better include a larger scale of patients.

\section{Conclusion:}

There is more prevalence of anaemia in females in Fayoum Governorate. This prevalence is increasing with age. In pregnant females the most common type of anaemia is IDA. There is a common association between anaemia with diabetes mellitus in absence of CKD.

\section{References:}

[1]: Stave E, (2015): The association between diet quality and prevalence of anemia in an urban population of socioeconomically diverse African American and white adults). ProQuest Dissertations \& Theses Global.

[2]: Stevens G, Finucane M, De-Regil L, et al., (2013): Global, regional, and national trends in haemoglobin concentration and prevalence of total and severe anaemia in children and pregnant and non-pregnant women for 1995-2011: a systematic analysis of population-representative data. Lancet Glob Health.; 1: E16-E25.

[3]: World Health Organization, (2011): global prevalence of anemia. Page 5, 6 .

[4]: Balarajan Y, Ramakrishnan U, Ozaltin E, et al., (2011): Anaemia in lowincome and middle-income countries, The Lancet; 378 (9809): 2123-2135.

[5]: Gandhi S, Hagans I, Nathan K, et al., (2017): Prevalence, Comorbidity and Investigation of Anemia in the Primary Care Office. J Clin Med Res.; 9(12):970-980. 
[6]: Callera F, Callera A, Silva A, et al., (2015): Prevalence of anemia in a sample of elderly southeastern Brazilians.rev bras hematol hemoter.; 3 7(1):43-47.

\section{[7]: El Arbagy A, Kora M, Barbary H, et} al, (2015): Recent advances in immunosuppression for kidney transplantation. Menoufia Medical Journal; 28(2) 272-281.

\section{[8]: Sharourou A, Hassan M, Teclebrhan} M, et al., (2018): Anemia: its Prevalence, Causes, and Management. The Egyptian Journal of Hospital Medicine; 70(10): sta1877-1879.

[9]: Al Hassan N, (2015): The prevalence of iron deficiency anemia in Saudi University female students. Journal of Microscopy and Ultrastructure.3(1)35-38.

[10]: Salama Z, Darweesh S, Shehab H, et al., (2016): Etiology and prevalence of fatigue in chronic liver disease: clinical view. The Egyptian Journal Of Internal Medicine; 28(2): 78-85.

[11]: Mengesha M and Dadi G, (2019): prevalence of anemia among adults at Hawassa University referral hospital, Southern Ethiopia BMC Hematology 19:1.

[12]: Zaninetti C, Klersy C, Scavariello C, et al., (2018): Prevalence of anemia in hospitalized internal medicine patients: Correlations with comorbidities and length of hospital stay. Eur J Intern Med.; 51:1117.

[13]: Portolés J, Gorriz J, Rubio E, et al., 2013: The development of anemia is associated to poor prognosis in NKF/KDOQI stage 3 chronic kidney disease. BMC Nephrol.; 14: 2. 